\title{
Analysis on Influence of the Dispersion Degree of PVA Fibers on Pavement Performance of Cement-Stabilized Macadam
}

\author{
Lingqing Yuan $\mathbb{D},{ }^{1}$ Naixing Liang $\mathbb{D},{ }^{1}$ and Chunhua $\mathrm{Zhao}^{2}$ \\ ${ }^{1}$ School of Civil Engineering, Chongqing Jiaotong University, Chongqing 400074, China \\ ${ }^{2}$ Chongqing Institute of Technology, Chongqing 401331, China \\ Correspondence should be addressed to Naixing Liang; liangnx@cqjtu.edu.cn
}

Received 12 July 2019; Revised 9 September 2019; Accepted 17 September 2019; Published 13 October 2019

Academic Editor: Claudio Mazzotti

Copyright (C) 2019 Lingqing Yuan et al. This is an open access article distributed under the Creative Commons Attribution License, which permits unrestricted use, distribution, and reproduction in any medium, provided the original work is properly cited.

In order to study the effect of PVA fiber dispersion on the performance of cement-stabilized macadam as pavement base material, the dispersion factor $F_{\mathrm{vc}}$ is introduced $\left(F_{\mathrm{vc}}=1-C_{\mathrm{vc}}, C_{\mathrm{vc}}\right.$ refers to dispersion coefficient of relative mass fraction proportion coefficient) as a factor to judge the dispersion degrees. Besides, the connections among $F_{\mathrm{vc}}$ and the compressive strength of the splitting strength of cement-stabilized macadam in various curing periods are analyzed. The research conclusions reveal that (1) when the mass ratio of PVA fibers to coal ash is higher than $1: 50$, resulting $F_{\mathrm{vc}}>0.95$, it means the PVA fibers can disperse evenly in the cement-stabilized macadam; (2) both the compressive strength and the cleavage strength of cement-stabilized macadam with PVA fibers are proportional to $F_{\mathrm{vc}}$; moreover, both the compressive strength and the splitting strength of cement-stabilized macadam with PVA fibers are obviously stronger than those in the common macadam; and (3) under the same curing period and with the same $F_{\mathrm{vc}}$ value, both the compressive strength and the splitting strength in the first type of cement-stabilized macadam (volume content: $0.9 \mathrm{~kg} / \mathrm{m}^{3}$ of PVA fibers) are stronger than those in the second type of cement-stabilized macadam (volume content: $0.6 \mathrm{~kg} / \mathrm{m}^{3}$ of PVA fibers).

\section{Introduction}

Choosing graded gravel as aggregate, filling the gaps of the aggregate with some amount of cementing material and with enough mortar, the cement-stabilized macadam is employed widely in road base level, since it possesses in itself many merits such as relatively high strength, good antiseepage ability, fine frost resistance ability, and so on. However, its shortcomings such as low flexural strength as well as low crack resistance ability result in early cracks, which constrain its sparking merits, together with its application longevity $[1,2]$.

Presently, the method [3-6] that adding fibers into cement-based materials to enhance its flexural strength as well as its crack resistance has been popular with many scholars from China, USA, and other developed nations. The fine toughness and relatively high modulus have enabled fibers to improve the properties of cement-based materials effectively during application. Khorami and Ganjian [7] discovered during research that when the mass of added agriculture waste fibers (such as bagasse, wheat, eucalyptus, and so on) is $4 \%$ of the cement mass, flexural behavior of the cementbased composite changes relatively obviously, not to mention that the properties of bagasse fibers are better than those of wheat and eucalyptus. Yang et al. [8-11] added polypropylene fiber into the cement-stabilized macadam, the result of which shows that the polypropylene fiber can improve its performance in contraction deformation and in flexural behavior. Yang et al. [12-15] and others added basalt fiber into the cement-stabilized macadam, the result of which shows that the basalt fiber can enhance the crack resistance and the fracture property of the macadam base. Xu et al. [16-18] added PVA fibers into the cement-stabilized macadam, the result of which shows that the PVA fibers bring higher load capacity and more flexible deformation properties, together with a hyperbolic contraction equation that presents precisely the drying shrinkages of super-high toughness cement base complex materials. According the 
research results [19], the compressive strength as well as the flexural behavior regarding concrete with silica fume and PVA fibers is stronger than that of common concrete; also, adding PVA fibers into the concrete can improve obviously the crack resistance of cement paste and concrete. Bengi et al. [20] studied brick wall painted with concrete to a conclusion that adding PVA fibers into solid, high-strength brick wall can increase around half of shear strength, the increased strength of which is 2.5 times higher than that found in common brick wall. Ghorbani's research [21, 22] suggests that replacing some cement with rice husk ash (RHA) can increase the unconfined compressive strength of cement-based composites. Jamsawang et al. [23] has found that the surface of steel is more hydrophilic than other synthetic fiber types. And it is denser in the cemented sand and the substrate has no separation interface area, which provides the best overall bending performance. Ma's studies [24] have shown that the addition of basalt fiber cement soil can increase the plastic behavior of the sample. Nevertheless, all the above examples only covers the content of considering the effect of the amount of fibers mixed on the properties of complex materials, instead of studying farther the effect brought by fiber factors on complex materials properties.

Some Chinese scholars have studied the dispersion of fibers. Cao et al. [25] studied the dispersion of PVA fibers by means of fluorescence microscope, image processing technology, and statistics. Yang et al. [26] researched the influences on carbon fibers' (from carbon fiber cement coating, i.e., CFCC) dispersion resulted from lengths, amounts, mixing processes, dispersant and water-cement ratio and so on, with ways such as fresh pulp method and resistance measurement of hardening specimens. Cao et al. $[27,28]$ studied dispersion of PVA fibers in cement-stabilized macadam, using image processing technology and statistics. Wang et al. [29] observed the fracture surface of carbon fiber concrete by means of scanning electron microscope, who also analyzed the distribution of factors from fracture surface with energy spectrum, as a dispersion study for carbon fiber distribution. Jie et al. [30] scanned the fracture surface with computerized tomography, and then classified the typical morphology of each component in the micrograph, and verified the distribution of the fiber with the grayscale recognition result of CT image. On the other hand, the above cases applied mainly image processing technology in scanning partial fracture surfaces of complex materials, with fiber (the diameter is very small) congealing with cement paste, thus resulting in a lack of credibility and perfection. As for resistance measurement of hardening specimens, this method can only work if the carbon fiber is conductive, thus not suitable for insulators such as PVA fibers.

PVA fibers possess strong strength and high modulus. Adding the PVA fibers into the cement-stabilized macadam can improve flexural strength as well as crack resistance, plus extending work longevity. Many scholars from China, USA, and other developed nations have achieved a lot in studying PVA fibers in cement-stabilized macadam, but the study on influence brought by the dispersion of PVA fibers requires further steps. In conclusion, this paper aims to study how the dispersion factor $F_{\mathrm{vc}}$ (from PVC fibers) affects the compressive strength as well as splitting strength of cementstabilized macadam in various curing periods, and then find out the connection in them.

\section{Studying Method}

2.1. Raw Materials. The marking number of the composite Portland cement employed in the experiment is p.c32.5, manufactured by Zhongshan Cor., Ltd in Xuzhou city, Jiangsu province, China. The testing result meets regulation and requirements, and the indexes are shown in Table 1 below. The aggregate (specifications: $0-5 \mathrm{~mm}, 5-10 \mathrm{~mm}$, $10-15 \mathrm{~mm}, 15-25 \mathrm{~mm}$, and $25-30 \mathrm{~mm}$ ) in the experiment is limestone coming from stone material factory in Chaoyang River, Chongqing city, China. The testing results show that the aggregates meet all mechanical performance requirements.

Table 2 shows the physical parameters of the PVA fiber taken in the test, and its appearance is shown in Figure 1.

The composite proportions in the experiment comply with requirements in Code for Aggregate Test of Highway Engineering JTG E42-2005. For data concerning the proportions, refer to Table 3.

2.2. Testing Methods. In this experiment, PVA fibers were treated by dry mixing and dispersing with the mass ratio of PVA fibers to coal ash of $1: 0,1: 25,1: 50$, and $1: 75$. The treatment equipment used a pure slurry mixer. Quantitative PVA fibers and coal ash were added into the mixing pot. The mixing rate was built-in low-speed mixing, and the mixing time was set to 3 minutes. After one minute of each stirring, the PVA fibers and coal ash in the mixing pot were manually turned over to ensure that the PVA fibers could be fully mixed with coal ash. The above blended PVA fibers were labeled as (1), (2), (3), and (4) PVA fibers in turn, and the coal ash used was first-class fly ash with a fineness of 320 meshes and a density of about $2.4 \mathrm{~g} / \mathrm{cm}^{3}$. According to the requirements of Test Methods of Materials Stabilized with Inorganic Binders for Highway Engineering (JTG E512009), the optimum moisture content and maximum dry density of cement-stabilized macadam material were determined by compaction test. The test results showed that the optimum moisture content of the cement-stabilized macadam material was $4.8 \%$ and the maximum dry density was $2.301 \mathrm{~g} / \mathrm{cm}^{3}$ when the cement content was $4 \%$.

The mixing test of (1) PVA fibers and cement-stabilized macadam was carried out. Four cement-stabilized macadam samples were selected for each mixing according to gradation design and compaction test results. The length of PVA fiber was $12 \mathrm{~mm}$, and the volume content was $0.6 \mathrm{~kg} / \mathrm{m}^{3}$ and $0.9 \mathrm{~kg} / \mathrm{m}^{3}$. After mixing test, one sample of cementstabilized macadam was taken to mark and place, and two samples were taken separately after repeating the above test. Finally, three labeled samples with volume doping of $0.6 \mathrm{~kg} /$ $\mathrm{m}^{3}$ and three labeled samples with volume doping of $0.9 \mathrm{~kg} /$ $\mathrm{m}^{3}$ were obtained. After repeating the above experiments, 18 
TABLE 1: Testing results of cement properties.

\begin{tabular}{|c|c|c|c|}
\hline \multicolumn{2}{|l|}{ Item } & Result & Technique requirements \\
\hline \multicolumn{2}{|l|}{ Fineness (\%) } & 4.0 & $\leq 10$ \\
\hline \multicolumn{2}{|c|}{ Water requirement of normal consistency (\%) } & 32.5 & Real value tested \\
\hline \multicolumn{2}{|c|}{ Initial setting time $(\mathrm{min})$} & 390 & $\geq 180$ \\
\hline \multicolumn{2}{|l|}{ Final setting time (min) } & 520 & $360 \leq h \leq 600$ \\
\hline \multicolumn{2}{|l|}{ Stability } & Eligible & - \\
\hline Strength after three days (MPa) & Compressive strength & $\begin{array}{c}18.1 \\
5.3\end{array}$ & $\geq 11$ \\
\hline Strength after 28 days $(\mathrm{MPa})$ & $\begin{array}{l}\text { Flexural strength } \\
\text { Compressive strength } \\
\text { Flexural strength }\end{array}$ & $\begin{array}{c}5.3 \\
39.7 \\
9.5\end{array}$ & $\begin{array}{l}\geq 2.5 \\
\geq 32.5 \\
\geq 5.5\end{array}$ \\
\hline
\end{tabular}

TABLE 2: Physical parameters of polyvinyl alcohol.

\begin{tabular}{lccc}
\hline Color & Diameter $(\mu \mathrm{m})$ & Fine density $(\mathrm{g} / 10000 \mathrm{~m})$ & Hot water resistance $\left({ }^{\circ} \mathrm{C}\right)$ \\
\hline Silvery white & 5 & $2.0 \pm 0.25$ & 100
\end{tabular}

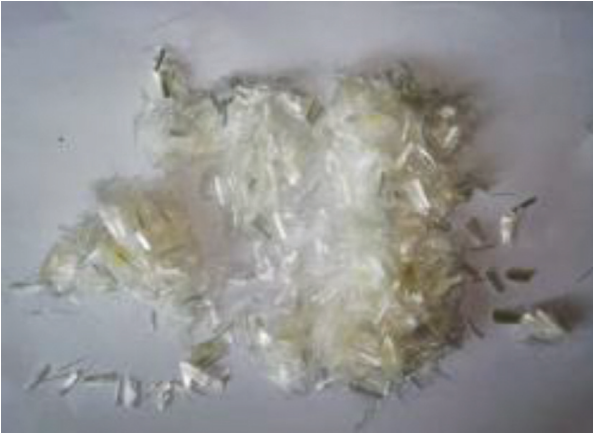

Figure 1: Polyvinyl alcohol fibers.

TABLE 3: Graded proportions of cement-stabilized macadam.

\begin{tabular}{lccc}
\hline \multirow{2}{*}{ Mesh size $(\mathrm{mm})$} & \multicolumn{3}{c}{ Graded proportions } \\
& Maximum & Minimum & Graded in synthesis \\
\hline 31.5 & 100 & 100 & 100.00 \\
26.5 & 98 & 93 & 98.00 \\
19 & 86 & 72 & 79.00 \\
9.5 & 58 & 47 & 52.52 \\
4.75 & 32 & 29 & 30.01 \\
2.36 & 19.7 & 17 & 17.73 \\
0.6 & 15 & 8 & 8.92 \\
0.075 & 3.5 & 0 & 3.50 \\
\hline
\end{tabular}

labeled samples with volume fraction of $0.6 \mathrm{~kg} / \mathrm{m}^{3}$ and $0.9 \mathrm{~kg} / \mathrm{m}^{3}$ of PVA fibers (2), (3), and (4) were obtained. Finally, 18 samples of PVA fibers and coarse aggregates with particle size of $9.5 \mathrm{~mm}$ were separated from the samples by water washing method. The separated PVA fibers and coarse aggregates were dried at $150^{\circ} \mathrm{C}$ in the laboratory oven and weighed at last.

The cement-stabilized macadam samples (samples that with PVA fibers and that without) were moulded into cylinders, as per Test Methods of Materials Stabilized with Inorganic Binders for Highway Engineering (JTG E512009). In experiments that study compressive strength and splitting strength, there were four kinds of PVA fibers employed (PVA fibers (1),(2),(3), and (4)), with volume content of $0.6 \mathrm{~kg} / \mathrm{m}^{3}$ and $0.9 \mathrm{~kg} / \mathrm{m}^{3}$. The curing temperature was for $20^{\circ} \mathrm{C} \pm 2^{\circ} \mathrm{C}$, with relative humidity no lower than $95 \%$. Setting curing period was 7 days, 28 days, and 90 days. Figure 2 was about moulded cement-stabilized macadam sample. As for the 25 specimens dried on the left, they had been used for compressive strength tests.

We conducted compressive strength test and splitting strength test to cement-stabilized macadam samples with electro-hydraulic bending and compression testing machine and universal testing machine. In the tests, the running velocity was kept at $1 \mathrm{~mm} / \mathrm{min}$, and the test processes are shown in Figures 3 and 4. There were six parallel samples, and the test result came from the average value of the six result values. We deleted the test values whose variation coefficient $C_{\mathrm{v}}$ was larger than or equal to $15 \%$, and replaced them with new test results using new samples.

2.3. Review Methods for PVA Fibers' Dispersion in CementStabilized Macadam. Choose the dispersion factor (which is $F_{\mathrm{vc}}$ ) of PVA fibers to review their dispersion. Here, $F_{\mathrm{vc}}=1-C_{\mathrm{vc}}, C_{\mathrm{vc}}$ refers to dispersion coefficient of relative mass fraction proportion coefficient. The "relative mass fraction proportion coefficient" [27] refers to ratio of the actual mass of PVA fiber to the corresponding theory mass value in the NO. I sample. The ratio of the actual mass of coarse aggregate to the corresponding theory mass is named as $C_{\mathrm{P} / \mathrm{gi}}$ (see formula (1)). The relative coarse aggregate mass fraction proportion coefficient is named as mass fraction proportion coefficient thereinafter (see formula (3)):

$$
\begin{aligned}
C_{\mathrm{P} / \mathrm{gi}} & =\frac{m_{\mathrm{pi}} / m_{\mathrm{p}}}{m_{\mathrm{gi}} / m_{\mathrm{g}}}, \\
C_{\mathrm{vc}} & =\frac{\sqrt{(1 / 3) \sum_{i=1}^{3}\left(C_{\mathrm{P} / \mathrm{gi}}-\overline{C_{\mathrm{P} / \mathrm{gi}}}\right)^{2}}}{\overline{C_{\mathrm{P} / \mathrm{gi}}}}, \\
F_{\mathrm{vc}} & =1-C_{\mathrm{vc}},
\end{aligned}
$$

where $m_{\mathrm{pi}}$ and $m_{\mathrm{gi}}$ are actual mass of PVA fibers (unit: g) and coarse aggregate (diameter: $9.5 \mathrm{~mm}$; unit: $\mathrm{kg}$ ) in the NO. I 


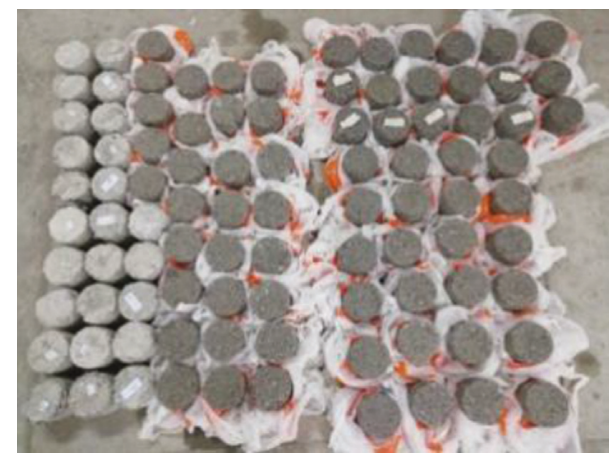

FIGURE 2: Formed cement-stabilized macadam specimens.

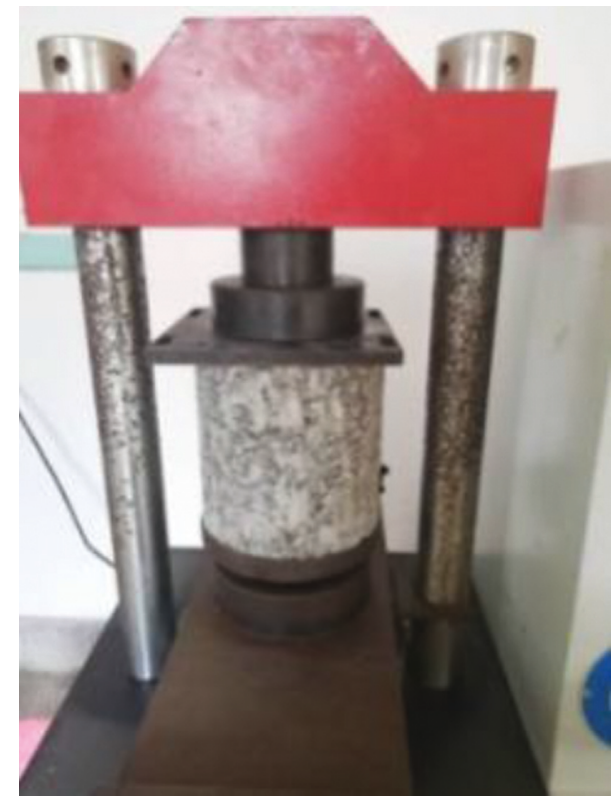

Figure 3: Compressive strength test for cement-stabilized macadam.

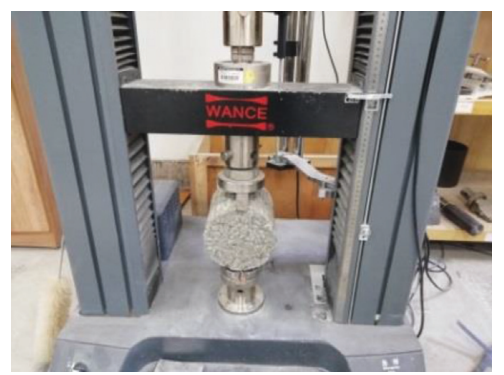

FIGURE 4: Splitting test for cement-stabilized macadam.

sample, respectively; $m_{\mathrm{p}}$ and $m_{\mathrm{g}}$ are theory mass of PVA fibers (unit: $g$ ) and coarse aggregate (diameter: $9.5 \mathrm{~mm}$; unit: $\mathrm{kg}$ ) in every sample, respectively; $\overline{C_{\mathrm{P} / \mathrm{gi}}}$ is the average value of mass fraction proportion coefficient in every sample; and $C_{\mathrm{vc}}$ is the dispersion coefficient of mass fraction proportion coefficient.

\section{Result Analysis}

3.1. Data Analysis regarding the Dispersion of PVA Fibers in Cement-Stabilized Macadam. The data are collected in Table 4.

Take the ratio of coal ash mass to PVA fibers mass as the abscissa, and the $F_{\mathrm{vc}}$ as the ordinate; see Figure 5 for their connection.

According to the conclusions from Figure 5 [31], when the coal ash is not added, the value $F_{\mathrm{vc}}$ is far larger than 0.5 , which means the value $F_{\mathrm{vc}}$ is far smaller than 0.95 , with the $C_{\mathrm{vp}}$ between the actual PVA fibers mass and the corresponding theory mass larger than 0.1 . Thus, it is concluded that the PVC fibers cannot disperse evenly in the cementstabilized macadam in the above case. However, when the mass ratio of PVA fibers to coal ash is of $1: 50$, then the $F_{\mathrm{vc}}$ is equal to 0.5 , the $F_{\mathrm{vc}}$ is equal to 0.95 , the $C_{\mathrm{vp}}$ is equal to 0.1 . Hence, it is concluded that the PVA fibers can disperse evenly exactly in the case. On the basis of the above two cases, it is concluded that when the ratio of PVA fiber mass to the coal ash mass is $1: 25$, the PVA fibers cannot disperse evenly. If the very ratio is $1: 75$, the conclusion is that the PVA fibers can disperse evenly. Thereinafter, we set the $F_{\mathrm{vc}}$ of 0.95 as a critical point, where the PVC fibers can disperse evenly exactly. When the value of $F_{\mathrm{vc}}$ is below 0.95 , the PVC fibers cannot disperse evenly, and vice versa. In addition, it is considered that there are no PVC fibers when the value of $F_{\mathrm{vc}}$ is of 0.75 , so as to facilitate analysis.

\subsection{Data Analysis on PVA Fibers Enhancing Mechanical Properties of Cement-Stabilized Macadam}

3.2.1. Compressive Experiment. Refer to Table 5 for test result. The results of converting the test results into $F_{\mathrm{vc}}$ and compressive strength are shown in Table 6 . The relationship between $F_{\mathrm{vc}}$ and compressive strength is shown in Figures 6 and 7.

According to the above Figure 6 (with fiber content as $0.6 \mathrm{~kg} / \mathrm{m}^{3}$, curing periods as 7 days, 28 days, and 90 days) and Figure $7, F_{\mathrm{vc}}$ is positively related to the compressive strength. The situation when the curing period is of 90 days and the fiber content is of $0.6 \mathrm{~kg} / \mathrm{m}^{3}$ is the only case studied here. The compressive strength value of the cement-stabilized macadam with evenly dispersed PVA fibers is around $4.8 \%$ higher than it in macadam where PVA fibers cannot disperse evenly, and is about $16.1 \%$ higher than it is in common cement-stabilized macadam. On the other hand, when the fiber content is of $0.9 \mathrm{~kg} / \mathrm{m}^{3}$, the compressive strength value of the cement-stabilized macadam with evenly dispersed PVA fibers is around 6.2\% higher than it is in macadam where PVA fibers cannot disperse evenly, and is about $17.8 \%$ higher than it is in common cement-stabilized macadam.

When the abscissa value $F_{\mathrm{vc}}$ is of 0.95 (a critical point), the PVA fibers can disperse evenly exactly in cement-stabilized macadam. It is concluded that when the value of $F_{\mathrm{vc}}$ is larger than 0.95, the PVA fivers have dispersed evenly; in the area between 0.75 and 0.95 , the PVA fivers unite groups by groups, and the lower the value of $F_{\mathrm{vc}}$, the more groups it can 
Table 4: Dispersion of PVA fibers.

\begin{tabular}{|c|c|c|c|c|c|c|c|c|c|c|}
\hline & \multicolumn{5}{|c|}{$0.6 \mathrm{~kg} / \mathrm{m}^{3}$} & \multicolumn{5}{|c|}{$0.9 \mathrm{~kg} / \mathrm{m}^{3}$} \\
\hline & $m_{\mathrm{pi}}$ & $m_{\mathrm{gi}}$ & $C_{\mathrm{vc}}$ & $C_{\mathrm{vp}}$ & $F_{\mathrm{vc}}$ & $m_{\mathrm{pi}}$ & $m_{\mathrm{gi}}$ & $C_{\mathrm{vc}}$ & $C_{\mathrm{vp}}$ & $F_{\mathrm{vc}}$ \\
\hline \multirow{3}{*}{$M_{\mathrm{PVA}} / M_{\text {Coal ash }}=1: 0$} & 1.48 & 1.60 & \multirow{3}{*}{0.1862} & \multirow{3}{*}{0.1863} & \multirow{3}{*}{0.8138} & 1.56 & 1.60 & \multirow{3}{*}{0.1893} & \multirow{3}{*}{0.1621} & \multirow{3}{*}{0.8107} \\
\hline & 1.5 & 1.55 & & & & 1.79 & 1.59 & & & \\
\hline & 0.97 & 1.57 & & & & 2.29 & 1.51 & & & \\
\hline \multirow{3}{*}{$M_{\mathrm{PVA}} / M_{\mathrm{Coal} \text { ash }}=1: 25$} & 1.61 & 1.61 & \multirow{3}{*}{0.1078} & \multirow{3}{*}{0.1336} & \multirow{3}{*}{0.8922} & 2.11 & 1.57 & \multirow{3}{*}{0.1292} & \multirow{3}{*}{0.146} & \multirow{3}{*}{0.8708} \\
\hline & 1.17 & 1.52 & & & & 1.67 & 1.53 & & & \\
\hline & 1.32 & 1.53 & & & & 1.5 & 1.51 & & & \\
\hline \multirow{3}{*}{$M_{\mathrm{PVA}} / M_{\text {Coal ash }}=1: 50$} & 1.42 & 1.61 & \multirow{3}{*}{0.0499} & \multirow{3}{*}{0.0986} & \multirow{3}{*}{0.9501} & 1.89 & 1.55 & \multirow{3}{*}{0.05} & \multirow{3}{*}{0.1} & \multirow{3}{*}{0.95} \\
\hline & 1.23 & 1.51 & & & & 2.11 & 1.64 & & & \\
\hline & 1.12 & 1.43 & & & & 1.65 & 1.45 & & & \\
\hline \multirow{3}{*}{$M_{\mathrm{PVA}} / M_{\text {Coal ash }}=1: 75$} & 1.33 & 1.57 & \multirow{3}{*}{0.017} & \multirow{3}{*}{0.0258} & \multirow{3}{*}{0.983} & 1.92 & 1.57 & \multirow{3}{*}{0.025} & \multirow{3}{*}{0.0383} & \multirow{3}{*}{0.975} \\
\hline & 1.35 & 1.56 & & & & 2.03 & 1.61 & & & \\
\hline & 1.27 & 1.53 & & & & 1.85 & 1.56 & & & \\
\hline
\end{tabular}

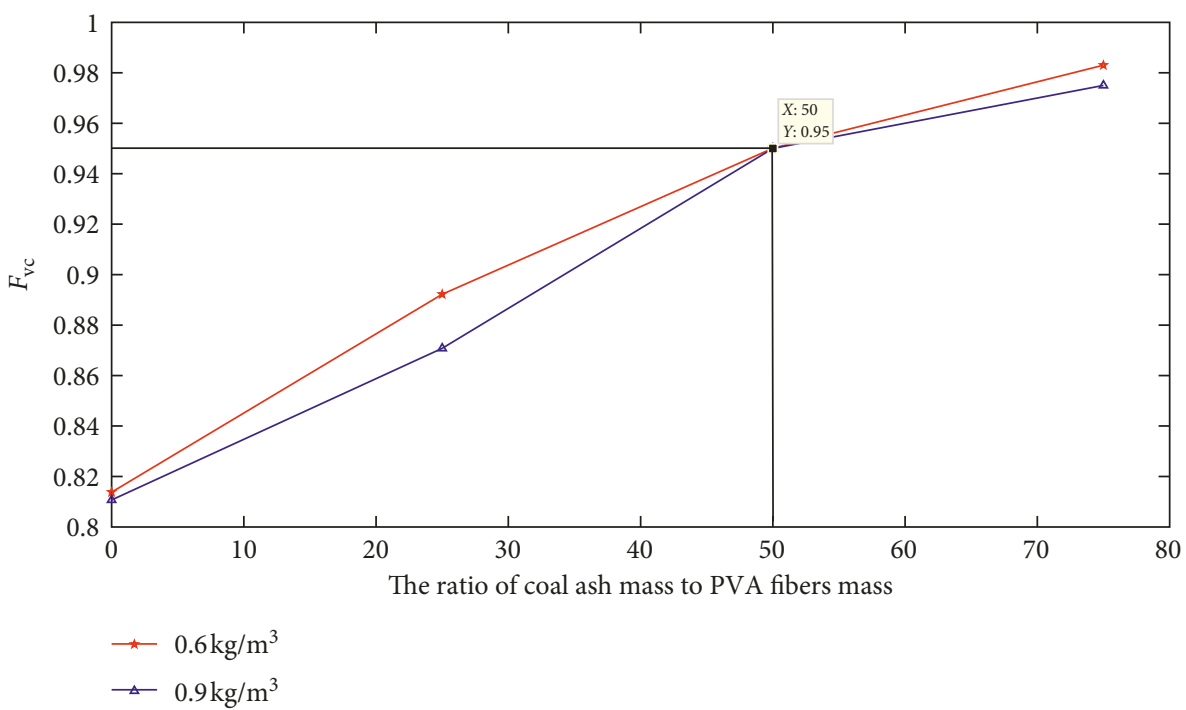

Figure 5: The connection between the ratio of coal ash mass to PVA fibers mass, with volume content of $0.6 \mathrm{~kg} / \mathrm{m}^{3}$ and $0.9 \mathrm{~kg} / \mathrm{m}^{3}$.

TABLE 5: Compressive strength test on cement-stabilized macadam.

\begin{tabular}{|c|c|c|c|c|c|c|c|c|c|c|c|c|}
\hline \multirow{2}{*}{$\begin{array}{l}\text { Fiber-adding content } \\
0-0\end{array}$} & \multicolumn{4}{|c|}{$\begin{array}{c}\text { Compressive strength }(\mathrm{MPa}) \\
(7 \mathrm{~d})\end{array}$} & \multicolumn{4}{|c|}{$\begin{array}{l}\text { Compressive strength (MPa) } \\
(28 \mathrm{~d})\end{array}$} & \multicolumn{4}{|c|}{$\begin{array}{c}\text { Compressive strength (MPa) } \\
(90 \mathrm{~d})\end{array}$} \\
\hline & 3.76 & 3.76 & & & & & & & & & & 5.66 \\
\hline $12-6$ & 4.14 & 4.18 & & & 5.72 & 5.75 & & 5.97 & 6.27 & & & 6.57 \\
\hline $12-9$ & 4.17 & 4.23 & 4.43 & 4.49 & 5.73 & 5.77 & 5.91 & 6.01 & 6.28 & 6.34 & 6.48 & 6.67 \\
\hline
\end{tabular}

TABLE 6: Connection between $F_{\mathrm{vc}}$ and compressive strength.

\begin{tabular}{lcccc}
\hline Fiber content $\left(\mathrm{kg} / \mathrm{m}^{3}\right)$ & $F_{\mathrm{vc}}$ & Compressive strength $(7 \mathrm{~d})$ & Compressive strength $(28 \mathrm{~d})$ & Compressive strength $(90 \mathrm{~d})$ \\
\hline 0 & 0.75 & 3.76 & 5.13 & 5.66 \\
\hline & 0.8138 & 4.14 & 5.72 & 6.27 \\
0.6 & 0.8922 & 4.18 & 5.75 & 6.34 \\
& 0.9501 & 4.39 & 5.81 & 6.45 \\
& 0.983 & 4.47 & 5.97 & 6.57 \\
0.9 & 0.8107 & 4.17 & 5.73 & 6.28 \\
& 0.8708 & 4.23 & 5.77 & 6.34 \\
& 0.95 & 4.43 & 5.91 & 6.48 \\
& 0.975 & 4.49 & 6.01 & 6.67 \\
\hline
\end{tabular}




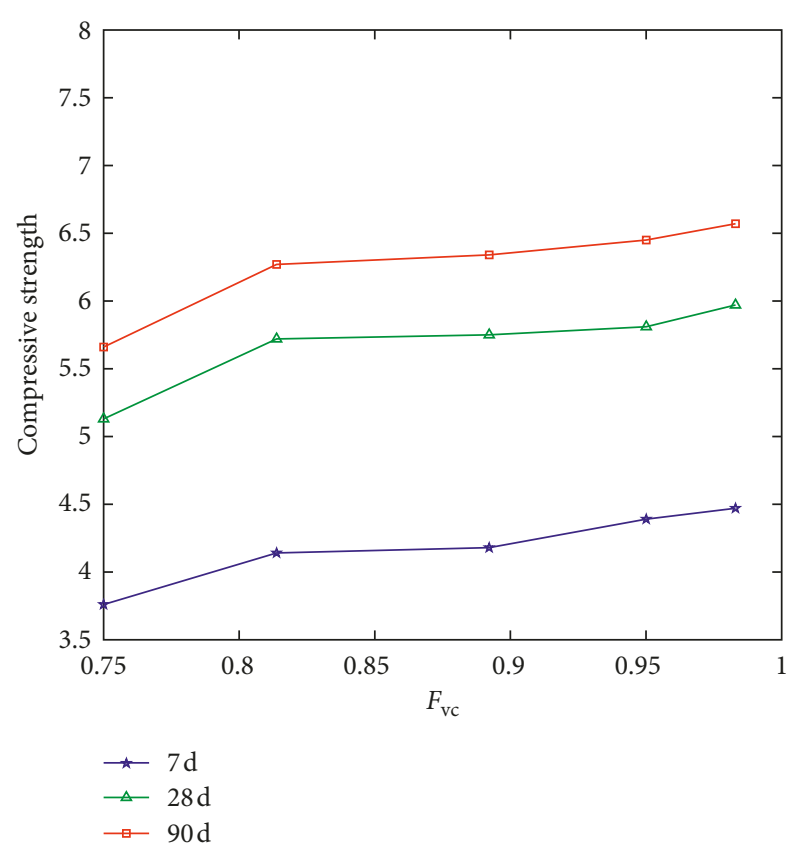

Figure 6: Relationship between $F_{\mathrm{vc}}$ and compressive strength in cement-stabilized macadam with PVA fiber content of $0.6 \mathrm{~kg} / \mathrm{m}^{3}$.

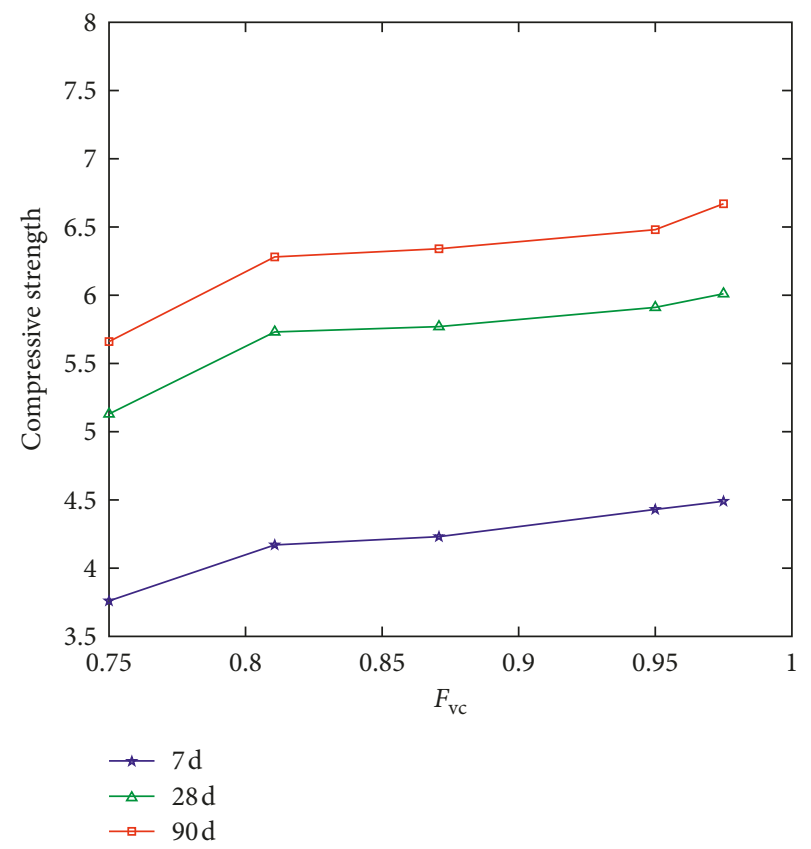

FIGURE 7: Relationship between $F_{\mathrm{vc}}$ and compressive strength in cement-stabilized macadam with PVA fiber content of $0.9 \mathrm{~kg} / \mathrm{m}^{3}$.

find, resulting in less dispersion. According to Figures 6 and 7, the compressive strength of cement-stabilized macadam added with PVA fibers is stronger than that of common cement-stabilized macadam, because the base will crack under outside force. According to Material Sheet Interface [32], for cement-stabilized macadam added in fibers, as shown in Figure 8, base cracks happen in several surfaces, together with interface debonding, fiber pull-out, the fracture of base as well as fibers. If the crack penetrates the surface,

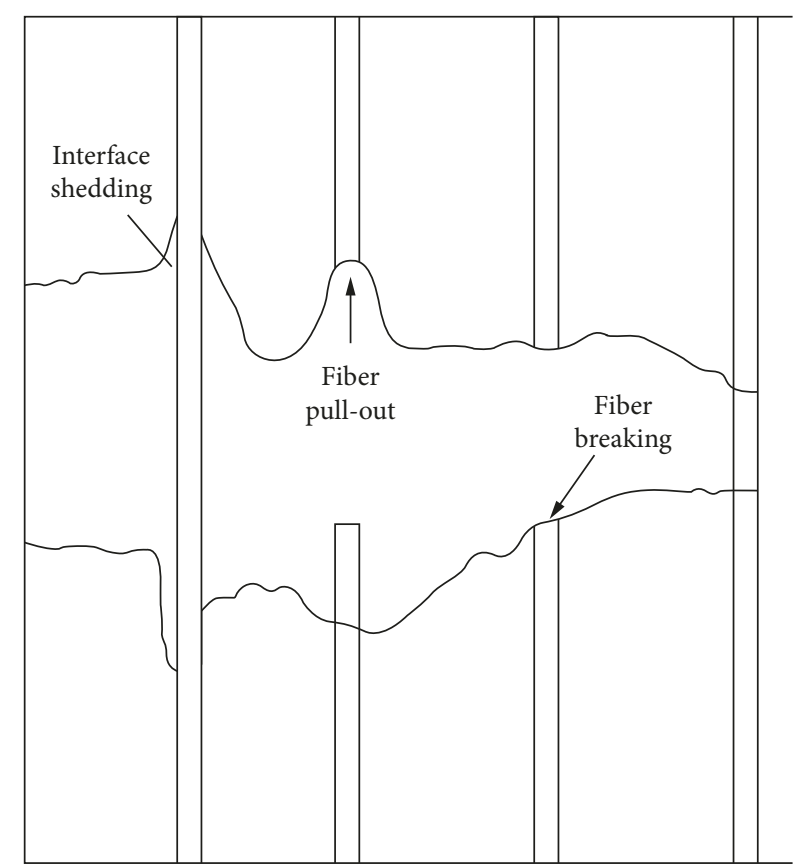

FIgURE 8: The damaging process of complex material.

then the material is damaged. In the process of damage, more energy is absorbed due to the existence of fibers. Thus, the macadam with fibers possesses higher compressive strength.

As mentioned in the last paragraph, when the value of $F_{\mathrm{vc}}$ is below 0.95 , there are many group-gathered PVA fibers distributed randomly in the macadam; so, the macadam fails to diverse and disperse the stress. The area with fiber groups becomes the point to cause or even start the crack. As the crack extends around, the macadam sample is damaged. When the value of $F_{\mathrm{vc}}$ is above 0.95 , according to Material Sheet Surface, the interface of composites contains threedimensional interfacial phases in the transition zone between two phases with only a few microns. The interfacial phase is very thin but has very complex structure. The chemical composition, thermal properties, and mechanical properties of the interfacial phase change gradiently. The interface microstructure together with its properties resulted from heat stress, interracial crystallization effect, and interface chemical effect during transition period will affect the macroscopic properties, enhancing properties of the complex materials. As a consequence, the more the PVA fibers disperse, the more the three-dimensional interface phrase will be, and the strength of the macadam will be higher.

We employ the software MATLAB to fit the $F_{\mathrm{vc}}$ (PVC fiber contents are of $0.6 \mathrm{~kg} / \mathrm{m}^{3}$ and $0.9 \mathrm{~kg} / \mathrm{m}^{3}$, with curing period of 90 days) with the compressive strength, and we get linear functions as follows:

$$
\begin{aligned}
y & =3.345 x+3.321, \\
R^{2} & =0.8287, \\
y & =3.718 x+3.047, \\
R^{2} & =0.8421 .
\end{aligned}
$$




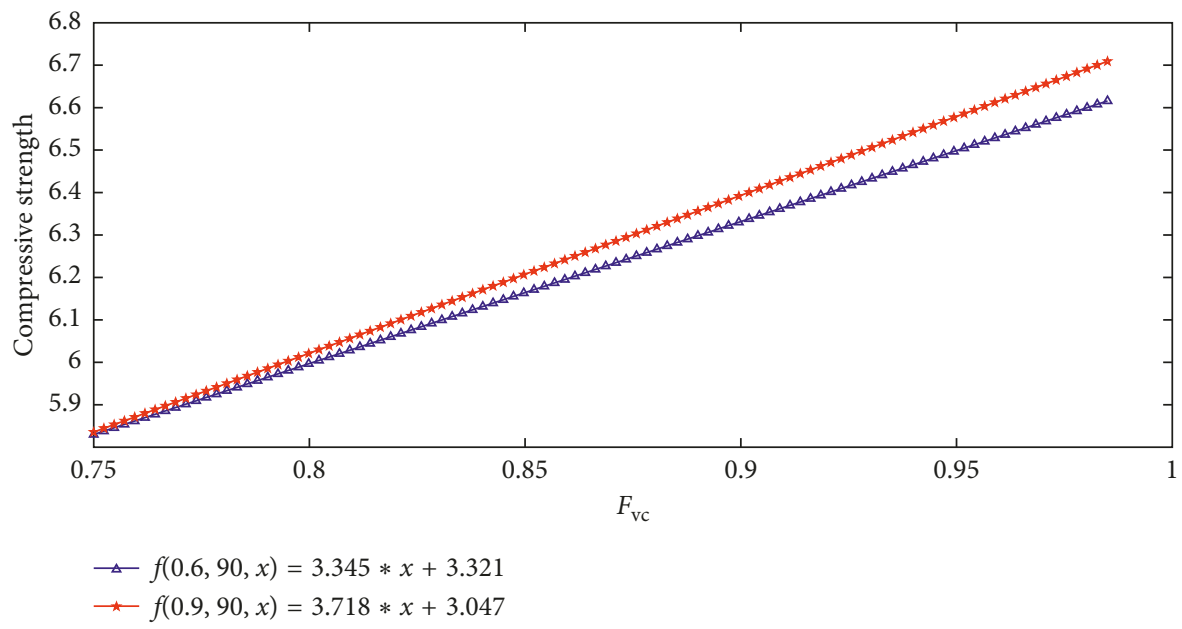

Figure 9: Relationship between $F_{\mathrm{vc}}$ and compressive strength under the curing age of $90 \mathrm{~d}$ and fiber volume of $0.6 \mathrm{~kg} / \mathrm{m}^{3}$ and $0.9 \mathrm{~kg} / \mathrm{m}^{3}$, respectively.

We use MATLAB to draw the two functions of the fit in the same picture, as shown in Figure 9. In Figure 9, when the curing period is of 90 days and the same $F_{\mathrm{vc}}$ value is chosen, the compressive strength of cement-stabilized macadam with PVA fiber of $0.9 \mathrm{~kg} / \mathrm{m}^{3}$ is stronger than that of cementstabilized macadam with PVA fiber of $0.6 \mathrm{~kg} / \mathrm{m}^{3}$. Thus, the content of PVA fibers can affect the compressive strength in the macadam, and in due scope they are positively related.

3.2.2. Splitting Experiment. The test results are listed in Table 7, and the corresponding connection between $F_{\mathrm{vc}}$ and splitting strength is in Table 8. See Figures 10 and 11 for the connection between $F_{\mathrm{vc}}$ and splitting strength.

The connection trends between splitting strength and dispersion factor $F_{\mathrm{vc}}$ are illustrated in Figure 10 (fiber content: $0.6 \mathrm{~kg} / \mathrm{m}^{3}$; curing periods of seven days, 28 days, and 90 days), and Figure 11 (fiber content: $0.9 \mathrm{~kg} / \mathrm{m}^{3}$; curing periods of seven days, 28 days, and 90 days). According to the two figures, $F_{\mathrm{vc}}$ is positively related to the splitting strength.

The situation when the curing period is of 90 days and the fiber content is of $0.6 \mathrm{~kg} / \mathrm{m}^{3}$ is the only case study here. The splitting strength value of the cement-stabilized macadam with evenly dispersed PVA fibers is around 5.6\% higher than it in macadam where PVA fibers cannot disperse evenly, and is about $22.6 \%$ higher than it in common cement-stabilized macadam. On the other hand, when the fiber content is of $0.9 \mathrm{~kg} / \mathrm{m}^{3}$, the splitting strength value of the cement-stabilized macadam with evenly dispersed PVA fibers is around 5.4\% higher than it in macadam where PVA fibers cannot disperse evenly, and is about $25.8 \%$ higher than it in common cement-stabilized macadam.

When the abscissa value $F_{\mathrm{vc}}$ is of 0.95 (a critical point), the PVA fibers can disperse evenly exactly in cement-stabilized macadam. The cement-stabilized macadam with fibers possesses higher splitting strength than that without fibers. Because the failure of cement-stabilized macadam without fibers is brittle failure, it is known from concrete fracture mechanics [33] that the fracture failure of brittle materials is the result of crack propagation that already exists. In another word, fracture degrees depend on the value stress force that widens the existing cracks. When the work created by outside force (i.e. strain energy) is more than the surface work that creates new surfaces during cracking, the existing cracks will extend automatically to fracture. Since PVA fibers enhance toughness, the splitting strength of cement-stabilized macadam with PVA fibers depends not only on the hydration intensity but also on the acting force between the fibers and the cement. The force between the PVA fibers and the cement includes the bite force between the fiber and the cement and the bonding between the fiber and the cement hydration product. As a result, the cleavage damage is a comprehensive result, and the splitting strength of cement-stabilized macadam with fibers will be obviously higher than that of cement-stabilized macadam without fibers.

For cement-stabilized macadam with fibers, when the value of $F_{\mathrm{vc}}$ is larger than 0.95 (in this condition, the PVA fibers have dispersed evenly), the cleavage damages cause the cracks inside the macadam to expand, together with the total system energy to decrease. The decreased energy is used for creating new free surfaces. The critical condition for cracks to expand is that the expanding force (i.e. strain energy release rate) is equal to the extension resistance (the extension resistance refers to the resistance created when the cracks are expanding to make free surfaces). The polymerhydration product three-dimensional net structure (created from reaction between PVA fibers and cement hydration product) enhances the extension resistance.

There are mainly three basic types of crack gap expansion under various loads according to fracture mechanics (Figure 12).

When the cement-stabilized macadam is damaged by splitting, the crack propagation type belongs to the type III outer shear type, and the stress field strength factor is as follows:

$$
\mathrm{KI}=Y \sigma \sqrt{c}
$$


TABLe 7: Test results of splitting strength in cement-stabilized macadam.

\begin{tabular}{lcccccccccccc}
\hline \multirow{2}{*}{ Fiber content } & \multicolumn{3}{c}{ Splitting strength $(\mathrm{MPa})(7 \mathrm{~d})$} & \multicolumn{3}{c}{ Splitting strength $(\mathrm{MPa})$} & $(28 \mathrm{~d})$ & \multicolumn{4}{c}{ Splitting strength $(\mathrm{MPa})(90 \mathrm{~d})$} \\
& 0 & $1: 25$ & $1: 50$ & $1: 75$ & 0 & $1: 25$ & $1: 50$ & $1: 75$ & 0 & $1: 25$ & $1: 50$ & $1: 75$ \\
\hline $0-0$ & 0.26 & 0.26 & 0.26 & 0.26 & 0.46 & 0.46 & 0.46 & 0.46 & 0.62 & 0.62 & 0.62 \\
$12-6$ & 0.31 & 0.31 & 0.33 & 0.34 & 0.53 & 0.54 & 0.58 & 0.58 & 0.72 & 0.72 & 0.74 & 0.76 \\
$12-9$ & 0.31 & 0.33 & 0.33 & 0.34 & 0.54 & 0.56 & 0.58 & 0.59 & 0.74 & 0.74 & 0.76 & 0.78 \\
\hline
\end{tabular}

TABLe 8: Connection between $F_{\mathrm{vc}}$ and splitting strength.

\begin{tabular}{lcccc}
\hline Fiber content $\left(\mathrm{kg} / \mathrm{m}^{3}\right)$ & $F_{\mathrm{vc}}$ & Splitting strength $(\mathrm{MPa})(7 \mathrm{~d})$ & Splitting strength $(\mathrm{MPa})(28 \mathrm{~d})$ & Splitting strength $(\mathrm{MPa})(90 \mathrm{~d})$ \\
\hline 0 & 0.75 & 0.26 & 0.46 & 0.62 \\
\hline \multirow{4}{*}{0.6} & 0.8138 & 0.31 & 0.53 & 0.72 \\
& 0.8922 & 0.31 & 0.54 & 0.72 \\
& 0.9501 & 0.33 & 0.58 & 0.74 \\
0.9 & 0.983 & 0.34 & 0.58 & 0.76 \\
& 0.8107 & 0.31 & 0.54 & 0.74 \\
& 0.8708 & 0.33 & 0.56 & 0.74 \\
& 0.95 & 0.33 & 0.58 & 0.76 \\
\end{tabular}

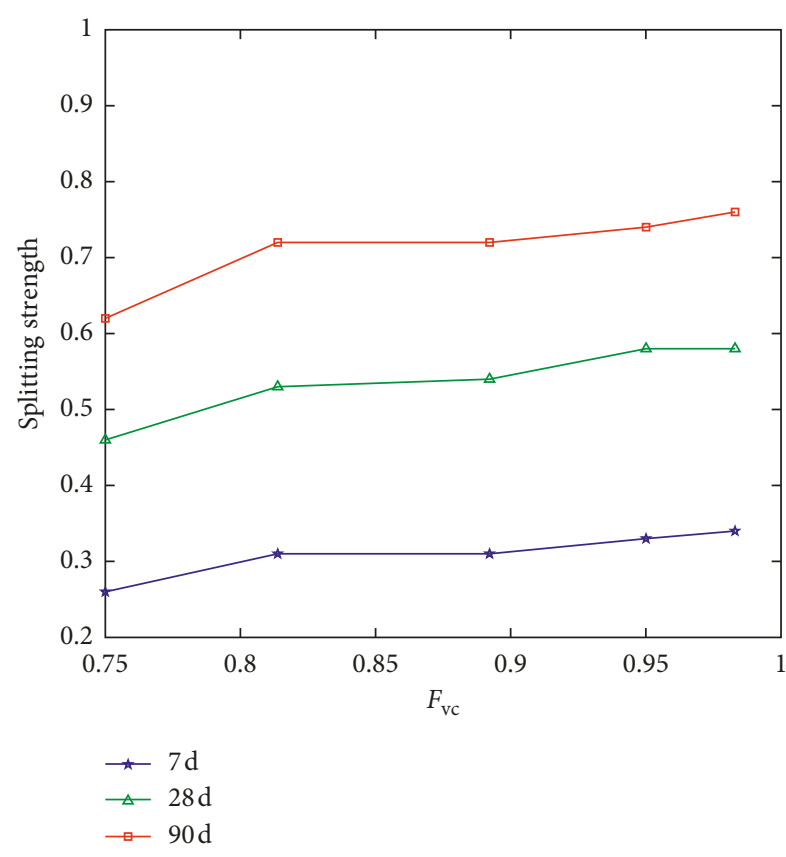

Figure 10: Relationship between $F_{\mathrm{vc}}$ and splitting strength in cement-stabilized macadam with PVA fiber content of $0.6 \mathrm{~kg} / \mathrm{m}^{3}$.

where KI refers to intensity factor that reflects the intensity of crack stress field and $Y$ refers to geometric shape factor, which is related to crack types and geometric shapes of samples.

The crack will be a key to KI when the cement-stabilized macadam and the stress remain the same to one another. When the value of $F_{\mathrm{vc}}$ is larger than 0.95 , the PVA fibers disperse evenly. Group gatherings will occur to PVA fibers if the value of $F_{\mathrm{vc}}$ decreases; so, more holes will appear in the cement-stabilized macadam, increasing the value of $c$. As a

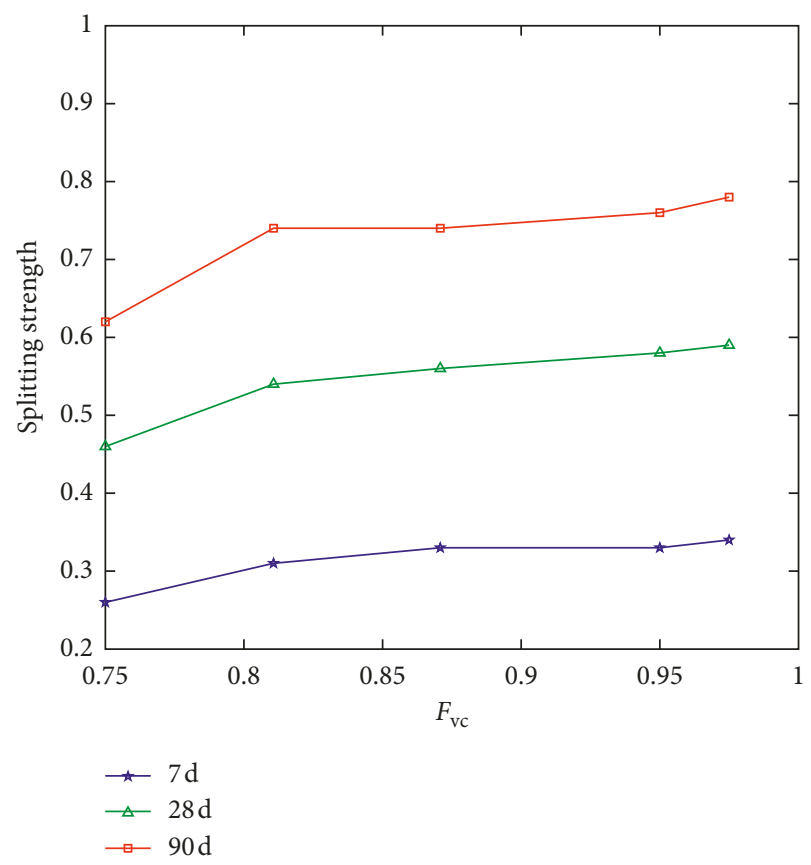

FIGURE 11: Relationship between $F_{\mathrm{vc}}$ and splitting strength in cement-stabilized macadam with PVA fiber content of $0.9 \mathrm{~kg} / \mathrm{m}^{3}$.

consequence, under same stress, the higher the dispersion degree of PVA fibers, the smaller the gaps as well as KI will be. According to fracture principles, brittle fracture happens when $\mathrm{KI}>\mathrm{KIc}$ (the second parameter refers to fracture toughness). Thus, the larger the value of $F_{\mathrm{vc}}$, the smaller the value of KI will be, resulting higher splitting strength, and vice versa.

We employ the software MATLAB to fit the $F_{\mathrm{vc}}$ (PVC fiber contents are of $0.6 \mathrm{~kg} / \mathrm{m}^{3}$ and $0.9 \mathrm{~kg} / \mathrm{m}^{3}$, with curing period of 90 days) with the splitting strength, and we get linear functions as follows: 


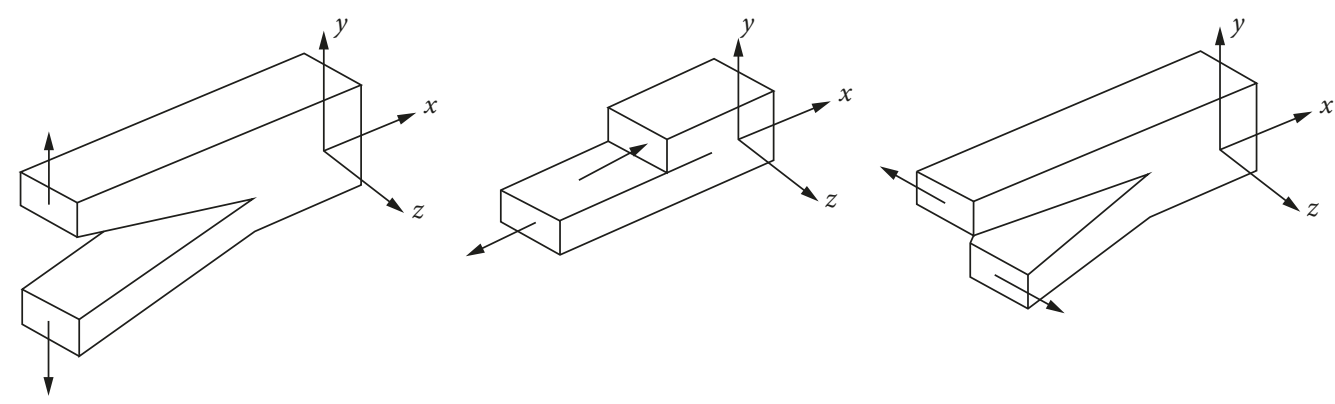

FIgURE 12: Basic types of crack expansion. (a) Split type I. (b) Staggerring type II. (c) Tearing type III.

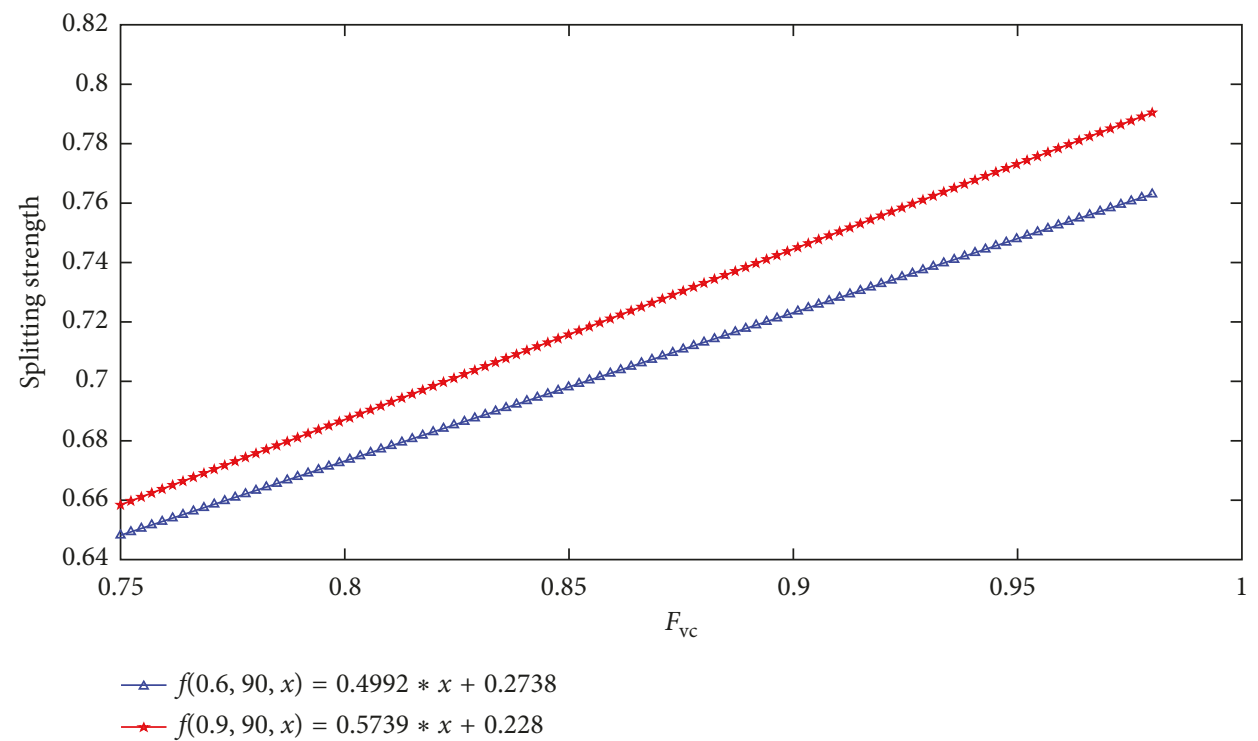

Figure 13: Relationship between $F_{\mathrm{vc}}$ and splitting strength under the age of $90 \mathrm{~d}$ and the volume of fiber volume of $0.6 \mathrm{~kg} / \mathrm{m}^{3}$ and $0.9 \mathrm{~kg} / \mathrm{m}^{3}$, respectively.

$$
\begin{aligned}
y & =0.4992 x+0.2738, \\
R^{2} & =0.7879, \\
y & =0.5739 x+0.228, \\
R^{2} & =0.7422 .
\end{aligned}
$$

The above two liner functions were drawn in the same drawing by MATLAB, as is shown in Figure 13. In Figure 13, when curing period is of 90 days, the splitting strength of cement-stabilized macadam with PVA fiber of $0.9 \mathrm{~kg} / \mathrm{m}^{3}$ is stronger than that of cement-stabilized macadam with PVA fiber of $0.6 \mathrm{~kg} / \mathrm{m}^{3}$. Thus, the content of PVA fibers can affect the splitting strength in the macadam, and in due scope they are positively related. Splitting strength has been one of the main indicators in road structure design, and the actual road surfaces are of aged period. In this case, the larger the value of $F_{\mathrm{vc}}$ is (i.e. the higher the dispersion degree is), the better it will be.

\section{Conclusions}

(1) The content of coal ash affects $F_{\mathrm{vc}}$ greatly. $F_{\mathrm{vc}}$ is positively related to the content ratios of coal ash.
When the mass ratio of PVA fibers to coal ash is larger than $1: 50$, then $F_{\mathrm{vc}}$ is larger than 0.95 . In this case, the PVA fibers can disperse evenly in the cement-stabilized macadam.

(2) Adding PVA fibers can improve the compressive strength of cement-stabilized macadam. When the fiber content is of $0.6 \mathrm{~kg} / \mathrm{m}^{3}$ and $0.9 \mathrm{~kg} / \mathrm{m}^{3}$, the compressive strength value of the cement-stabilized macadam with evenly dispersed PVA fibers is around $4.8 \%$ and $6.2 \%$ higher, respectively, than it is in macadam where PVA fibers cannot disperse evenly. On the other hand, the compressive strength value of the cement-stabilized macadam with PVA fibers is around $16.1 \%$ and $17.8 \%$ higher than it is in common cement-stabilized macadam (where PVA fibers do not exist). Moreover, under the same curing period, the compressive strength of the cementstabilized macadam with $0.9 \mathrm{~kg} / \mathrm{m}^{3}$ of PVA fiber content is stronger than that in cement-stabilized macadam with $0.6 \mathrm{~kg} / \mathrm{m}^{3}$ of PVA fiber content.

(3) Adding PVA fibers can improve the splitting strength of cement-stabilized macadam. When the 
fiber content is of $0.6 \mathrm{~kg} / \mathrm{m}^{3}$ and $0.9 \mathrm{~kg} / \mathrm{m}^{3}$, the splitting strength value of the cement-stabilized macadam with evenly dispersed PVA fibers is around $5.4 \%$ and $5.6 \%$ higher, respectively, than it is in macadam where PVA fibers cannot disperse evenly. On the other hand, the splitting strength value of the cement-stabilized macadam with PVA fibers is around $22.6 \%$ and $25.8 \%$ higher than it is in common cement-stabilized macadam (where PVA fibers do not exist). Moreover, under the same curing period and with the same $F_{\mathrm{vc}}$, the splitting strength of the cementstabilized macadam with $0.9 \mathrm{~kg} / \mathrm{m}^{3}$ of PVA fiber content is stronger than that in cement-stabilized macadam with $0.6 \mathrm{~kg} / \mathrm{m}^{3}$ of PVA fiber content.

\section{Data Availability}

The float data used to support the findings of this study are included in the article. All the data of this experiment are available from the corresponding author upon request.

\section{Conflicts of Interest}

The authors declare that they have no conflicts of interest.

\section{Acknowledgments}

This research was funded by the Yunnan Transportation Technology Fund Project (2017 (A) 15) and the Yunnan Provincial Transportation Technology Fund Project (2018).

\section{References}

[1] Y. Zu, S. L. Xu, and J. Zhao, "Experimental study of fracture properties of concrete matrix materials," Journal of Dalian University of Technology, vol. 51, no. 4, pp. 549-554, 2011.

[2] M. Yang, "Study of crack resistance on cement stabilized macadam base with mixed basalt fiber," Master thesis, Northeast Forestry University, Heilongjiang, China, 2011.

[3] P. Zhang, C. H. Liu, and Q. F. Li, "Experimental study on mechanical properties of cement stabilized crushed stones reinforced with polypropylene fiber," Journal of Zheng Zhou University (Engineering Science), vol. 31, no. 5, pp. 44-47, 2010.

[4] C. X. Li, "Material properties study on cement stabilized macadam with polyvinyal alcohol fibers," Journal of Transport Science and Engineering, vol. 34, no. 1, pp. 19-22, 2018.

[5] Y. F. He, "Mechanics and fracture resistance properties study on cement stabilized macadam with polyvinyal alcohol (PVA) fibers," Master thesis, Chongqing Jiaotong University, Chongqing, China, 2016.

[6] P. Tong, "Materials and structure properties study on cement stabilized macadam with PVA fibers," Master thesis, Chongqing Jiaotong University, Chongqing, China, 2017.

[7] M. Khorami and E. Ganjian, "Comparing flexural behaviour of fibre-cement composites reinforced bagasse: wheat and eucalyptus," Construction and Building Materials, vol. 25, no. 9, pp. 3661-3667, 2011.

[8] H. H. Yang, J. X. Wang, P. W. Hao, and J. L. Dai, "Applying fibers in the base layer of cement stabilized macadam," Journal of Chang'an University (Natural Science Edition), vol. 26, no. 3, pp. 14-20, 2006.
[9] P. Zhang, Q. F. Li, and J. Shen, "Fracture energy research and study on cement stabilized macadam with polypropylene fiber," Journal of South China University of Technology (Natural Science Edition), vol. 36, no. 6, pp. 72-77, 2008.

[10] X. C. Wang, "Compressive strength study on polypropylene fibers improving the compressive strength of cement stabilized macadam," Highway, vol. 5, pp. 130-132, 2007.

[11] Y. Ma, J. Gu, Y. Li, and Y. Li, "The bending fatigue performance of cement-stabilized aggregate reinforced with polypropylene filament fiber," Construction and Building Materials, vol. 83, pp. 230-236, 2015.

[12] M. Yang, "Study on the Road performance of basalt-polypropylene hybrid cement stabilized gravel," Master thesis, Chang'an University, Shanxi, China, 2017.

[13] Y. B. Bao, "Properties study on cement stabilized macadam with basalt fiber," Master thesis, Chang'an University, Shanxi, China, 2017.

[14] Y. Zheng, P. Zhang, Y. Cai, Z. Jin, and E. Moshtagh, "Cracking resistance and mechanical properties of basalt fibers reinforced cement-stabilized macadam," Composites Part B: Engineering, vol. 165, pp. 312-334, 2019.

[15] Y. Wen and W. Chen, "Early crack resistance and impervious performance research on concrete with PVA fibers," Journal of Shenyang Jianzhu University (Natural Science), vol. 34, no. 2, pp. 267-274, 2018.

[16] S. L. Xu and H. D. Li, "A review on the development of research and application of ultra high toughness cementitious composites," China Civil Engineering Journal, vol. 41, no. 6, pp. 45-60, 2008.

[17] S. L. Xu and Z. F. Liu, "Drying shrinkage behavior of ultra high toughness cementitious composites and its influence on anti-cracking capacity," Shuili Xuebao, vol. 41, no. 12, pp. 1491-1496, 2010.

[18] S. L. Gao, "Study on pseudo strain-hardening and fracture characteristic of polyvinyl alcohol fiber reinforced cementitious composites," Master thesis, Dalian University of Technology, Liaoning, China, 2006.

[19] L. Wang, S. H. Zhou, Y. Shi, S. W. Tang, and E. Chen, "Effect of silica fume and PVA fiber on the abrasion resistance and volume stability of concrete," Composites Part B: Engineering, vol. 130, pp. 28-37, 2017.

[20] A. Bengi, E. Emre, and D. Ali, "Strengthening of brick masonry with PVA fiber reinforced cement stucco," Construction and Building Materials, vol. 79, pp. 255-262, 2015.

[21] A. Ghorbani and M. Salimzadehshooiili, "Dynamic characterization of sand stabilized with cement and RHA and reinforced with polypropylene fiber," Journal of Materials in Civil Engineering, vol. 31, no. 7, Article ID 04019095, 2019.

[22] A. Ghorbani, M. Salimzadehshooiili, J. Medzvieckas, and R. Kliukas, "Strength characteristics of cement-rice husk ash stabilised sand-clay mixture reinforced with polypropylene fibers," The Baltic Journal of Road and Bridge Engineering, vol. 13, no. 4, pp. 447-474, 2018.

[23] P. Jamsawang, T. Suansomjeen, P. Sukontasukkul, P. Jongpradist, and D. T. Bergado, "Comparative flexural performance of compacted cement-fiber-sand," Geotextiles and Geomembranes, vol. 46, no. 4, pp. 414-425, 2018.

[24] Q. Ma and C. Gao, "Effect of basalt fiber on the dynamic mechanical properties of cement-soil in SHPB test," Journal of Materials in Civil Engineering, vol. 30, no. 8, Article ID 04018185, 2018.

[25] L. Cao, Y. P. Li, and F. S. Zheng, "Quantity review method for PVA fibers dispersion in engineered cementitious composite 
(ECC)," The Chinese and Foreign Road, vol. 33, no. 4, pp. 310-315, 2013.

[26] Y. X. Yang, Q. Z. Mao, D. R. Shen, and Z. Q. Li, "Study on the dispersion of fiber in carbon fiber cement composites," Journal of Building Materials, vol. 4, no. 1, pp. 84-88, 2001.

[27] Y. W. Cao, Y. N. Li, N. X. Zheng, Q. Wang, and Y. C. Zhou, "Detection technology of mixing uniformity of PVA fiber cement stabilized macadam," Journal of Highway and Transportation Research and Development, vol. 36, no. 2, pp. 7-27, 2019.

[28] Y. W. Cao, Y. Zhao, Q. Wang, Z. L. Xia, and N. X. Zheng, "Mixing uniformity of cement stabilized macadam with PVA fiber," Journal of Chongqing Jiaotong University (Natural Science), vol. 37, no. 5, pp. 29-33, 2018.

[29] C. Wang, G. S. Jiao, B. L. Li et al., "Dispersion of carbon fibers and conductivity of carbon fiber-reinforced cement-based composites," Ceramics International, vol. 43, no. 17, pp. 15122-15132, 2017.

[30] J. Gao, A. M. Sha, Z. J. Wang et al., "Characterization of carbon fiber distribution in cement-based composites by computed tomography," Construction and Building Materials, vol. 177, pp. 134-147, 2018.

[31] J. X. Wei, "Evenness study on cement stabilized macadam mixed with PVA fiber beams," Master thesis, Chongqing Jiaotong University, Chongqing, China, 2016.

[32] F. Z. Hu, G. R. Chen, and Y. J. Du, Material Sheet Surface, South China University of Technology Press, Shanghai, China, 2001.

[33] H. M. Zhang, Fracture Mechanics, China University of Mining and Technology Press, Jiangsu, China, 2018. 


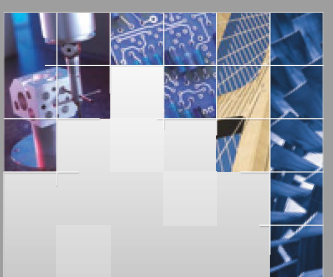

\section{Enfincering}
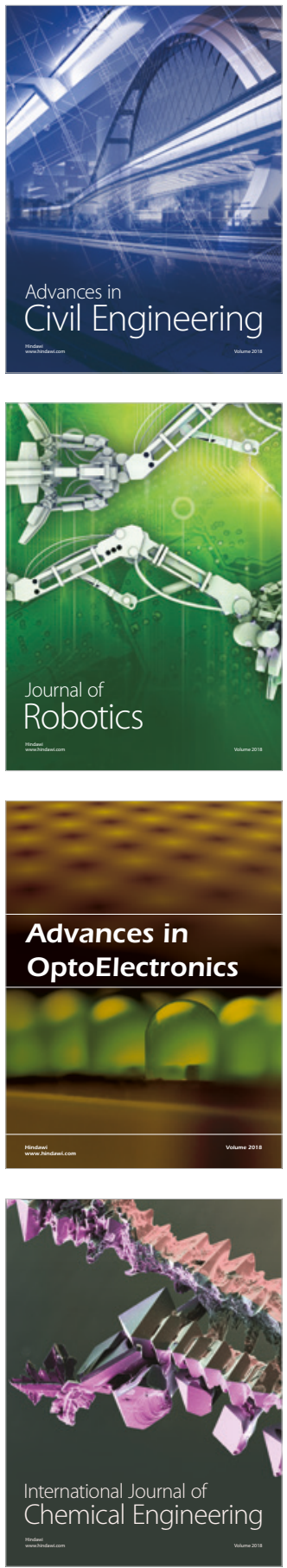

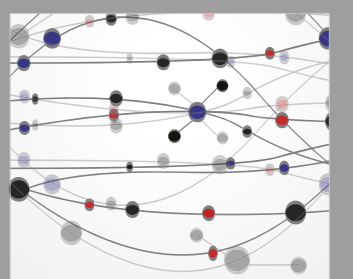

\section{Rotating \\ Machinery}

The Scientific World Journal

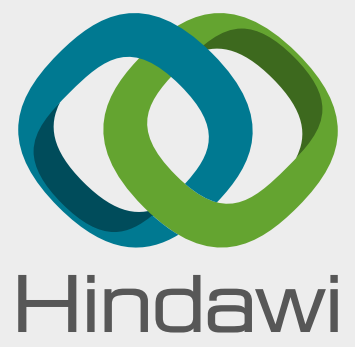

Submit your manuscripts at

www.hindawi.com
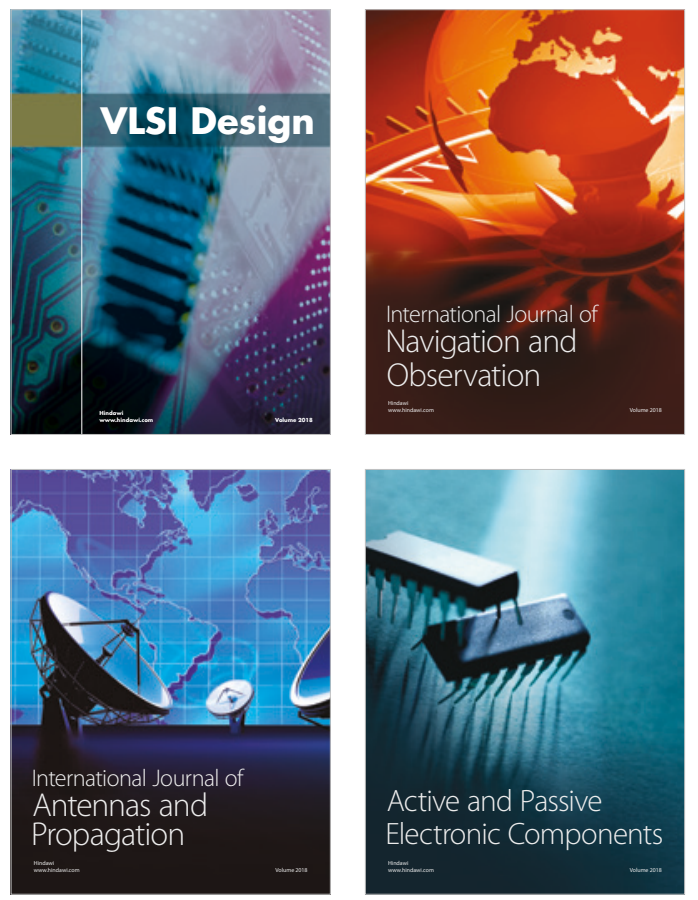
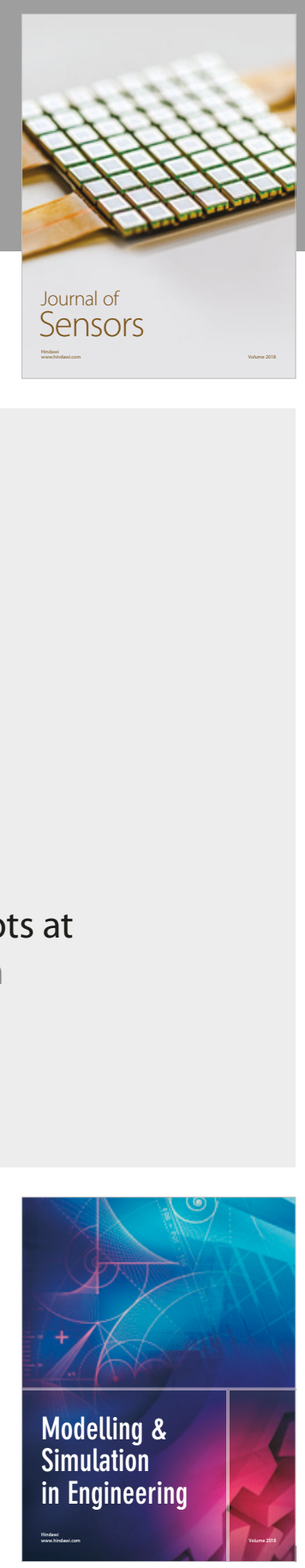

\section{Advances \\ Multimedia}
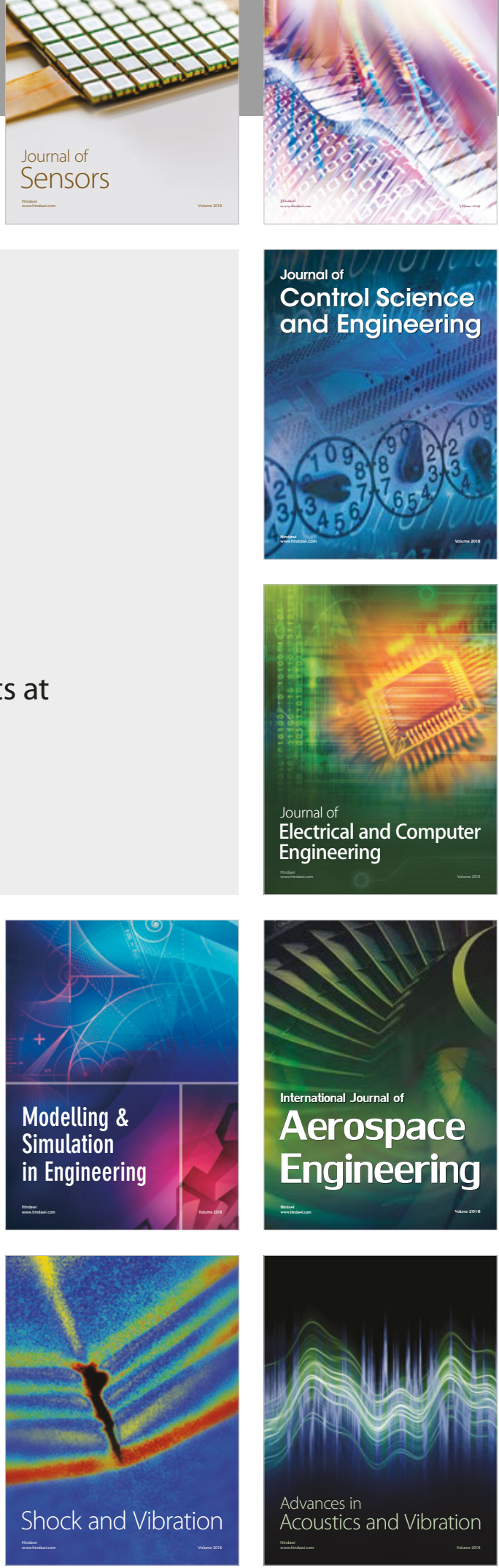